\title{
The Role of Negative Evidence in the Acquisition of Sociocultural Aspects of First Language
}

\author{
Farzaneh Dehghan \\ Shiraz University, Iran \\ Email: s-fdehghan@rose.shirazu.ac.ir
}

\begin{abstract}
Children learn their native language in a relatively rapid time and are able to communicate from very early using language. But is the acquisition of their native culture and native language dependent on each other (LeVine \& Norman, 2001; Riesman, 1993)? The present study aims to investigate the extent to which parents provide their children with direct and indirect negative feedback while they are acquiring sociocultural aspects of their language. A group of parents $(N=75)$ from three social backgrounds were interviewed. The results showed that parents used direct negative feedback more than indirect negative evidence while correcting a culturally inappropriate utterance (calling parents by their first names). Also it was found that parents from middle class socioeconomic status used more direct negative evidence than parents from a working class background who showed no significant difference regarding the use of different types of negative feedback. These results show the importance of negative feedback in the acquisition of sociocultural and pragmatic aspects of the native language.
\end{abstract}

Index Terms — first language acquisition, culture, negative evidence, culture acquisition

\section{INTRODUCTION}

Language acquisition is one of the great achievements in human cognitive development. All normal children in normal environments learn to talk. This fact can reveal innate capacities of the human species that make language acquisition possible, but, at the same time, it may reflect the social and cultural environment that provides children with the necessary input. Accordingly, the study of language acquisition and development could be studied from two different and largely separate approaches. The internal approach (Chomsky, 1985; cited in Lust, 2006) focuses on the mental mechanisms that make language acquisition possible. The external approach (Bronfenbrenner, 1988; cited in Hoff, 2006), on the other hand, emphasizes the role of the social context in which children live. The social contexts are "a nested set of systems surrounding the child ... includ[ing] culture, socioeconomic status, and ethnicity" (Hoff, 2006, p. 56). These systems shape the social contexts which are the sources of the child's interaction with the world and "these interactions are the primary engines of development" (Hoff, 2006, p. 56).

Within the external paradigm, sociocultural theory or social-interactionist theory is the most outstanding. This theory is an approach to language acquisition which emphasizes the environment and the context in which the language is being learned (Lantolf \& Thorne, 2007). It focuses on the pragmatics of language rather than grammar. The prominent theorist associated with interactionist theory is Lev Vygotsky (1978). Interactionists focus on Vygotsky's (1978) model of collaborative learning. In this approach, the novice speaker and the experienced speaker -in the case of language acquisition a child and a parent or caretaker- interact in a negotiated arrangement where feedback is always possible (Shaffer, Wood, \& Willoughby, 2002). Interactionists believe that linguistic knowledge is the internalization of behaviors which are learned in social interactions. Children exposed to samples of language in its social use learn that language can be used to regulate social interactions. Gradually, they internalize the external function of language (regulating social interactions) to regulate their own cognitive activity (the internal function of language) (Johnson \& Johnson, 1999).

Sociocultural theory argues that human mental functioning is fundamentally a mediated process that is organized by cultural artifacts, activities, and concepts (Lantolf and Thorne, 2007). Within this framework, humans are perceived to utilize existing cultural artifacts and create new ones that allow them to regulate their biological and behavioural activity. Lantolf and Thorne (2007, p. 197) define the theoretical foundations of this theory as follows:

Practically speaking, developmental processes take place through participation in cultural, linguistic, and historically formed settings such as family life and peer group interaction, and in institutional contexts like schooling, organized sports activities, and work places, to name only a few. SCT argues that while human neurobiology is a necessary condition for higher order thinking, the most important forms of human cognitive activity develop through interaction within these social and material environments.

The basic application of this approach is the importance it places on home and cultural environment in early childhood language acquisition. Language, according to this theory, develops in negotiation with the environment a child is facing. The nature of the social interactions that provide children with speech and the qualities of the speech developed, are shaped by larger social and cultural variables. In other words, input plays an important role in language 
acquisition and development according to this theory. This means that children need to experience what really occurs (or does not occur) in a language. This is referred to as positive or negative evidence or feedback (Lust, 2006). Some scholars (Chomsky, 1980; Ritchie \& Bhatia, 1998; Lust, 2006) have rejected the direct role of positive and negative evidence in first language acquisition. However, as Kasper and Blum-Kulka (1993, p. 28) quote from Gleason and Perlmann:

Unlike the acquisition of syntax, semantics, and even some sociolinguistic rules, when it comes to speaking politely adults do not leave it to the child to construct the rules on his or her own. Here, they take an active, even energetic part in directly instructing their children in the use of the various politeness devices. (Gleason \& Perlmann, 1985, p. 102)

This means that contrary to other aspects of linguistic knowledge, children need to be instructed directly regarding the sociocultural aspects of language. In this way both positive and negative evidence seem to be important in developing the socialization process.

\section{BACKGROUND OF THE STUDY}

\section{A. The Acquisition of Culture}

The child's acquisition of culture, or enculturation, has been the subject of much research. Children acquire the local culture of the community in which they live alongside their language. Two broad approaches have been adopted regarding culture acquisition (LeVine \& Norman, 2001). One group assert that culture acquisition occurs early in infancy (LeVine et al, 1994; cited in LeVine \&Norman, 2001). The other group (Riesman, 1993; Shweder, 1991; cited in LeVine \& Norman, 2001) reject infant enculturation and believe that culture acquisition occurs after language acquisition. But as LeVine and Norman (2001) state, there is evidence which supports the first idea of infant enculturation:

Our hypothesis is that parents of a particular culture tend to promote infant behaviours they see as consistent with their culture's model of virtue, and further, that they are successful enough on average that their children manifest selected behaviours at a "precociously" early age ... (p. 84)

One of these behaviours could be language. The social interactionist view is an approach to language acquisition based on culture and environment. Thus, language is not universal in scope. In fact, the theory holds that language is never universal, but context- and time-bound (LeVine \& Norman, 2001). On the one hand, this means that language seems to be always local, but also practical, since it develops exactly in the environment where it is most needed and most likely to be understood. On the other hand, the basic comprehension remains only at the level of the initial environment. Transition of this understanding to other environments becomes a problem (Wertsch, 1985). This means that specific cultural and social contexts shape the way language is developed. In other words, social interactionist view holds that parent-child interactions shape the child's linguistic competence through what is called zone of proximal development (ZPD) (Daniel, 2005).

Vygotsky defined the concept of the zone of proximal development (ZPD) as the distance between children's "actual developmental level as determined by independent problem solving" and their higher level of "potential development as determined through problem solving under adult guidance or in collaboration with more capable peers" (Vygotsky 1978, cited in Daniel, 2005). This view could also be applied to all aspects of language. Hence, vocabulary, for example, is bound by context or by the culture within which speech is necessary and understandable. Interactionists such as Bruner (1983) suggest that the language behaviour of adults when talking to children (known as child-directed speech or CDS) is especially adapted to support the acquisition process. This support is often described as scaffolding for the child's language learning. Interactionists argue that children are born with a powerful brain that matures slowly and predisposes them to acquire new understandings to get motivated to share with others (Tomasello, 1995). Local culture is one of these commonalities that parents and children try to share from very early (Tomasello, 2000).

\section{B. Culture and Language Acquisition}

The most controversial idea about language and culture is related to what is called language determinism, language relativism or Sapir-Whorf hypothesis (Brown, 2007). The strong form of this hypothesis (language determinism) holds that language determines culture or world view. Though this strong idea was rejected by scholars in the field especially cognitive psychologists and grammar universalists (e.g., Brown and Lenneberg, 1954; Guiora, 1981, cited in Brown, 2007; Pinker, 1994, 2007), a new (weak) version of this idea is now commonly referred to as language socialization theory.

Language socialization is the process in which children are socialized both through language and to use language within a community (Ochs and Schieffelin 1984; Schieffelin and Ochs 1986, Kulik and Shieffelin, 2004) on culturally relevant communicative practices and activities. As Fletcher and MacWhinney (1996, p. 4) assert, "although cultures appear to differ markedly in the extent to which they support language learning through grammatical specification, children all begin to master the core aspects of linguistic structure in the third year." Ochs and Schieffelin (1996) believe that direct engagement in socially meaningful and appropriate activities make children pick up language. Therefore, if a grammatical form is a part of a socially valued activity and if children are encouraged to learn that form, it will inevitably be learned. 
Language socialization view holds that the acquisition of linguistic forms is adjusted to certain cultural realities that influence how, when and why young children use and understand linguistic forms (Ochs and Schieffelin, 1996). Thus mere exposure is not a sufficient condition for language learning. A language socialization model rejects reducing the sociocultural context as mere "input" to be quantified and correlated with children's grammatical patterns. Rather, as Ochs and Schieffelin (1996, p. 73) believe it is the fact that linguistic forms show "culturally organized situations of use" and that children learn these forms through interaction with their caregivers and parents and not simply because these forms are more frequent in children's input.

\section{Input and the Acquisition of the Sociocultural Aspects of Language}

In the last few decades, research has demonstrated that the quantity and quality of the language input addressed to a child has an influence on the acquisition of language as a system (Kapur, 1994; Thomas, 2002). As was mentioned earlier, input could be positive (what actually occurs) and negative (what does not occur) in a child's environment.

Studies on language socialization show that the communicative abilities of children develop through their parents' direct attention and awareness. Demuth (1986) shows the importance of reminding customs used by parents to teach appropriate verbal behaviour to their children. These practices play an important role in the social development of Basotho children. Ochs (1986) reports how the Samoan caregivers use prosodic strategies to teach children ways to interpret affect-bound utterances. Clancy (1986) shows how Japanese mothers utilize questions and declarative prompts simultaneously to socialize their children's development in indirectness. Watson-Gegeo and Gegeo (1986) portray how Kawara'ae parents use repeating practices to teach children what to say and when to say it.

Based on our discussion earlier, it was found that direct negative and positive evidence is necessary in teaching sociocultural aspects of language contrary to other aspects like syntax or semantics where research has suggested no direct role for positive or negative input (Lust, 2006). However, there are not many studies regarding the role of different types of evidence in the acquisition of sociocultural aspects of language. On this basis, the present study aimed to investigate the extent to which parents provided their children with negative evidence (direct or indirect) while encountering an inappropriate social or cultural norm. In other words, it tried to investigate the role of input incorporating positive or negative feedback in the acquisition of cultural aspects of language. Also another aim of this study was to investigate the extent to which the socio-economic status of parents influenced the type of input provided to their children.

\section{THE STUDY}

\section{A. Population Sampling}

In order to collect data a group of parents $(\mathrm{N}=117)$ who had children aged between 18-36 months old were interviewed. A social norm in Iranian culture (addressing parents or caregivers by their first name) was selected to be investigated. From the above pool of parents spoken to initially, 75 parents who had noticed this issue in the language development of their children were selected for the purpose of this study based on their social class. This group were divided into three social groups based on parents' literacy level and their monthly income $(1=$ higher-middle, $\mathrm{N}=25,2=$ lower-middle, $\mathrm{N}=25$ and $3=$ working class, $\mathrm{N}=25$ ).

\section{B. Instrumentation, Result and Data Elicitation}

In the next phase the selected group $(\mathrm{N}=75)$ were interviewed by the researcher. They were asked about their reaction to this culturally inappropriate phenomenon and whether they corrected the child's utterance directly or just ignored it altogether (indirect negative feedback). As children in an Iranian context never hear such a form in their home and social environments, the type of feedback provided by their parents and caregivers will be negative (either direct or indirect).

\section{Data Analysis and Discussion}

As there were frequencies of people in three social classes and two types of feedback (direct negative and indirect negative), Chi-square data analysis procedure was run to see whether the differences obtained between the frequencies were statistically significant or not. Table 1 summarizes the results obtained for the three social classes and the total group:

TABLE 1:

CHI- SQUARE RESULTS FOR SOCIAL CLASSES AND TYPES OF EVIDENCE

\begin{tabular}{|l|l|l|l|l|}
\hline CHI- SQUARE RESULTS FOR SOCIAL CLASSES AND TYPES OF EVIDENCE \\
\hline 1 & direct & indirect & $\mathrm{X}^{2}$ & sig \\
\hline 2 & 21 & 4 & $11.56^{*}$ & .001 \\
\hline 3 & 23 & 2 & $17.64^{*}$ & .000 \\
\hline total & 15 & 10 & 1.00 & .31 \\
\hline
\end{tabular}

$1=$ higher-middle, $2=$ lower-middle, $3=$ working class 
As Table 1 reveals, the total significance reported by the computer is less than $.05(\mathrm{p}<.05)$. Therefore, it can be concluded that the differences in the evidence type between the three social classes is not accidental. In other words, social class had a significant effect on the use of different types of feedback (direct and indirect) by parents.

The comparison between direct and indirect negative categories also indicates that parents from the first two social classes mostly used direct negative feedback when they encounter a socially inappropriate form. This is especially the case with the second group (lower-middle class) as Table 1 indicates. The only exception is related to the third group (working class). As Table 1 shows, the $\mathrm{X}^{2}$ value is not significant for this group. In other words, parents from this social class did not use direct negative feedback significantly more than they used indirect negative feedback as was the case with the other two groups. Nearly all parents (regardless of the type of feedback they had used) asserted that children used this culturally inappropriate form less and less until it had been eliminated totally.

These findings confirm Gleason and Perlmann's (1985) idea that cultural and pragmatic aspects of language need direct instruction on the part of parents contrary to other aspects of language acquisition. In this way, direct negative evidence is also an important technique parents utilize in order to teach inappropriate strategies and communication norms dependent on their native culture.

\section{CONCLUSION AND SUGGESTIONS FOR FURTHER RESEARCH}

The results of this study confirmed the fact that direct negative evidence does play a role in the acquisition of sociocultural and pragmatic aspects of language. Parents provide their children (even as young as 24 months) with direct negative evidence when they encounter culturally and pragmatically inappropriate utterances. Indirect negative evidence also plays an important role as children do not hear such utterances in their environment. As the findings of this study revealed, the socio-economic status of the parents also has an effect on the type of evidence they provide for their children. Direct negative feedback is more common in middle class family groups while working class parents did not use either of the two types of feedback significantly.

As there are different social, cultural and pragmatic aspects of every particular language in the world, other research could be conducted to investigate the type of evidence provided to children while learning sociocultural and politeness strategies of the native culture. The role of other variables like socio-economic status, bilingualism, language prestige, code switching could also be investigated.

\section{REFERENCES}

[1] Bronfenbrenner, U. (1988). Interacting systems in human development. Research paradigms: present and future. In N. Bolger, A. Caspi, G. Downey, \& M. Moorehouse (Eds.), Persons in context: Developmental Processes (pp. 25-49). New York: Cambridge University Press.

[2] Brown, D. H. (2007). Principles of language learning and teaching. NY: Addison Wesley Longman, Inc.

[3] Brown, R., \& Lenneberg, E. (1954). A Study in Language and Cognition. Journal of Abnormal and Social Psychology, 49, 454-462.

[4] Bruner, J. (1983). Child's Talk: Learning to Use Language. New York: Norton.

[5] Chomsky, N. (1986). Knowledge of Language: Its Nature, Origin, and Use. New York: Praeger Publishers.

[6] Chomsky, N. (1980). Rules and Representations. NY: Columbia University Press.

[7] Clancy, P. (1986). The acquisition of communicative style in Japanese. In Scheiffelin, B. B. \& Ochs, E. (Eds.), Language socialization across culture, (pp. 213-49). Cambridge: Cambridge University Press.

[8] Daniels, H. (2005). An introduction to Vygotsky. Sussex: Routledge.

[9] Demuth, K. (1986). Prompting routines in the language socialization of Basotho children. In Schieffelin, B. B. \& Ochs, E. (Eds.), Language socialization across cultures, (pp. 51-79). Cambridge: Cambridge University Press.

[10] Fletcher, P. \& MacWhinney, B. (1996). The handbook of child language. Cambridge, MA: Blackwell Publications.

[11] Gleason, J., \& Perlmann, R. (1985). Acquiring social variation in speech. In H. Giles \& R. St. Clair (Eds.), Recent advances in language, communication, and social psychology. London: Lawrence Erlbaum.

[12] Hoff, E. (2006). How social contexts support and shape language development. Developmental Review: 26, 55-88.

[13] Johnson, K, \& Johnson, H. (1999). Encyclopedic dictionary of applied linguistics. Massachusetts, Blackwell Publishers Ltd.

[14] Kasper, G. \& Blum-Kulka, S. (1993). Interlanguage Pragmatics. Oxford: Oxford University Press.

[15] Kulick, D. \& Schieffelin, B. B. (2004). Language socialization. In A. Duranti (ed.) A companion to linguistic anthropology, 349-368. Malden, MA: Blackwell.

[16] Kapur, S. (1994). Some applications of formal learning theory results to natural language acquisition. In B. Lust, M. Suner and J. Whitman, (eds.), Syntactic theory and first language acquisition: Cross-linguistic perspectives. Hillsdale, NJ: Lawrence Erlbaum Associates, 491-508.

[17] Lantolf, J. P. \& Thorne, S. L. (2007). Sociocultural theory and second language learning. In Van Patten, B \& Williams, J. (Eds.), Theories in Second Language Acquisition: An Introduction (pp. 197-219). Mahwah: Lawrence Erlbaum Associates.

[18] LeVine, R. A. \& Norman, K. (2001). The infant's acquisition of culture: Early attachment reexamined in anthropological perspective. In Moore, C.C. \& Mathews, H. F. (Eds.), The psychology of cultural experience (pp. 83-104). Cambridge: Cambridge University Press.

[19] LeVine, R. A., LeVine, S., Dixon, S., Ritchman, A., Leiderman, P. H., Keefer, C. H., \& Brazelton. (1994). Child care and culture: lessons from Africa. Cambridge: CUP.

[20] Lust, B. (2006). Child language: Acquisition and growth. Cambridge: Cambridge University Press. 
[21] Ochs, E. (1986). From feelings to grammar: A Samoan case study. In Schieffelin, B. B. \& Ochs, E. (Eds.), Language socialization across cultures (251-272). Cambridge: Cambridge University Press.

[22] Ochs, E. \& Schieffelin, B. B. (1984). Language acquisition and socialization: three developmental stories and their implications." In R. Shweder \& R. LeVine (Eds.), Culture theory: essays on mind, self and emotion, 276-320. New York: Cambridge University Press.

[23] Ochs, E. \& Schieffelin, B. B. (1996). The impact of language socialization on grammatical development. In Fletcher, P. \& MacWhinney, B. (Eds.), The handbook of child language. (pp. 73-94). Cambridge, MA: Blackwell Publications.

[24] Pinker, S. (1994). The language instinct: How the mind creates language. NY: William Morrow.

[25] Pinker, S. (2004). The stuff of thought: Language as a window into human nature. NY: Penguin Group.

[26] Ritchie, W. C. \& Bhatia, T. J. (1998). Handbook of child language acquisition. California, San Diego: Academic Press.

[27] Shaffer, D. R., Wood, E., \& Willoughby, T. (2002). Developmental psychology: Childhood and adolescence (First Canadian Edition). Scarborough, Ont: Nelson/Thomson Canada Ltd.

[28] Schieffelin, B, B. \& Ochs, E. (1986). Language socialization across cultures. New York: Cambridge University Press.

[29] Shweder, R. A. (1991). Thinking through cultures: Expeditions in cultural psychology. Cambridge, MA: Harvard University Press.

[30] Thomas, M. (2002). Development of the concept of 'The poverty of the stimulus'. The Linguistic Review, 19, 51-72.

[31] Tomasello, M. (1995). Joint attention as social cognition. In Moore, C. and Dunham, P., (Eds.), Joint attention: its origins and role in development. Lawrence Erlbaum Associates.

[32] Tomasello, M. (2000). The cultural origins of human cognition. Cambridge, MA: Harvard University Press.

[33] Vygotsky, L. (1978). Mind in Society: The Development of Higher Psychological Processes. Cambridge, MA: Harvard Univ. Press

[34] Watson-Gegeo, K. and Gegeo, D. (1986). Calling out and repeating routines in the language socialization of Basotho children." In Schieffelin, B. B. \& Ochs, E. (Eds.), Language socialization across cultures, (pp. 17-50). Cambridge: Cambridge University Press.

[35] Wertsch, J. V. (1985). Vygotsky and the social formation of mind. Cambridge, MA: Harvard University Press.

Farzaneh Dehghan is a Ph.D candidate in TEFL at Shiraz University, Shiraz, Iran. Her research interests include reading and writing, literacy, testing, learning strategies and teacher education. She has publications on learning strategies and teacher education. 